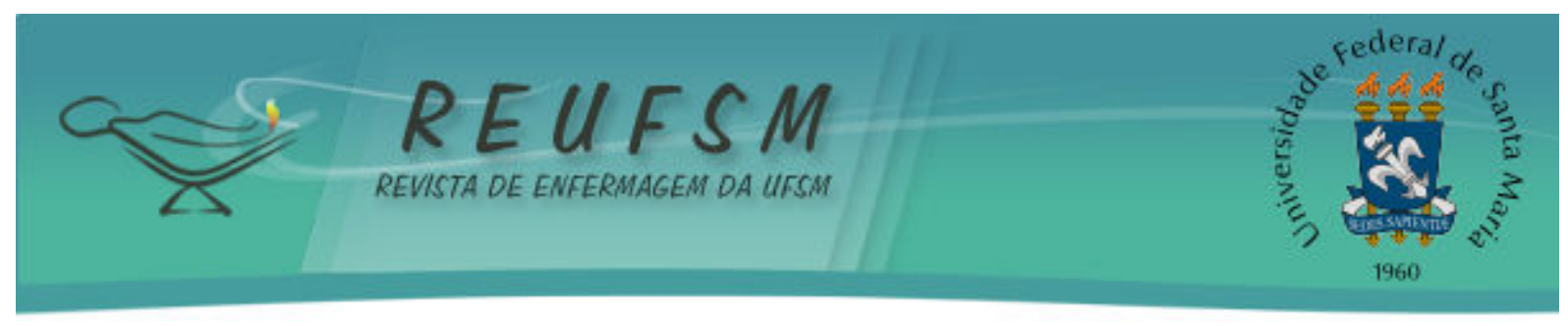

ARTIGO ORIGINAL

\title{
A VIVÊNCIA DA SEXUALIDADE POR MULHERES NO CLIMATÉRIO
}

THE EXPERIENCE OF WOMEN'S SEXUALITY IN CLIMACTERIC

LA EXPERIENCIA DE LA SEXUALIDAD DE MUJERES EN EL CLIMATÉRICO

\author{
Sheila Milena Pessoa dos Santos ${ }^{1}$ \\ Roberta Lima Golçalves ${ }^{2}$ \\ Elisangela Braga de Azevedo ${ }^{3}$ \\ Ana Karla Dantas Pinheiro ${ }^{4}$ \\ Carolina Araújo Barbosa ${ }^{5}$ \\ Kamila Nóbrega de França Costa ${ }^{6}$
}

Doi: $10.5902 / 217976928819$

RESUMO: Objetivo: analisar a vivência de mulheres no climatério com foco na sexualidade. Método: estudo analítico-descritivo, de natureza qualitativa, realizado com 16 mulheres com faixa etária entre 35 e 65 anos, usuárias de uma unidade básica de saúde da família. A coleta de dados ocorreu em dezembro de 2010 por meio de entrevista semiestruturada. Os dados foram analisados segundo a análise de conteúdo temática. A pesquisa cumpriu os requisitos para pesquisas com seres humanos, sendo aprovada pelo CEP, CAAE $n^{\circ}$ 0484.0.133.000-10. Resultados: verifica-se que a vivência da sexualidade no climatério possui influência dos padrões culturalmente construídos em torno da identidade feminina, que relegam o papel da mulher à satisfação do parceiro e à reprodução. Considerações finais: necessita-se que a enfermagem desenvolva atividades de educação em saúde, promovendo a discussão de temas relativos à sexualidade como corpo, gênero e violência, objetivando incentivar reflexões que desconstruam estereótipos de feminilidade e masculinidade.

Descritores: Saúde da mulher; Climatério; Sexualidade; Identidade de gênero.

ABSTRACT: Aim: to analyze women's life experiences in the climacteric period with a focus on sexuality. Method: analytical-descriptive study according to qualitative approach. The sample consisted of 16 women aged between 35 to 65 years-old, patients of public health system. The collection of data occurred in December of 2010 through the technique of semi-structured interview. The data has been addressed according to the analysis of the thematic content. The work has complied with the requisites for research with human beings, approved by CEP, CAAE $n^{\circ}$ 0484.0.133.000-10. Results: it has been

\footnotetext{
${ }^{1}$ Enfermeira. Mestre em Educação. Professora Assistente do Curso de Enfermagem do Centro de Ciências Biológicas e da Saúde da Universidade Federal de Campina Grande. Membro do Grupo de Pesquisa em Saúde e Enfermagem (NUPESEN-CNPq).Campina Grande/Paraíba/ Brasil. Email: Sheila.milena@gmail.com

${ }^{2}$ Enfermeira. Mestre em Saúde Pública. Professora Assistente do Curso de Enfermagem do Centro de Ciências Biológicas e da Saúde da Universidade Federal de Campina Grande. Membro do Grupo de Pesquisa em Saúde e Enfermagem (NUPESEN-CNPq). Campina Grande/Paraíba/ Brasil. Email: berttalima@gmail.com

${ }^{3}$ Enfermeira. Doutoranda em Enfermagem pela Universidade Federal da Paraíba. Professora do Departamento de enfermagem da Faculdade de Ciências Médicas de Campina Grande, PB. Campina Grande/Paraíba/ Brasil. Email: elisaaz@terra.com.br

${ }^{4}$ Graduanda do Curso de Enfermagem do Centro de Ciências Biológicas e da Saúde da Universidade Federal de Campina Grande. Aluna Bolsista do Programa de Educação pelo Trabalho para Saúde da Linha de Ação Saúde da Mulher com Ênfase no Climatério. Campina Grande/Paraíba/ Brasil. Email: karlinhadp@hotmail.com

${ }^{5}$ Graduanda do Curso de Enfermagem do Centro de Ciências Biológicas e da Saúde da Universidade Federal de Campina Grande. Aluna Bolsista do Programa de Educação pelo Trabalho para Saúde da Linha de Ação Saúde da Mulher com Ênfase no Climatério. Campina Grande/Paraíba/ Brasil. Email: carol_araujo_barbosa@hotmail.com ${ }^{6}$ Graduanda do Curso de Fisioterapia do Centro de Ciências Biológicas e da Saúde da Universidade Estadual da Paraíba. Aluna Voluntária do Programa de Educação pelo Trabalho para Saúde da Linha de Ação Saúde da Mulher com Ênfase no Climatério. Campina Grande/Paraíba/ Brasil. Email: kamilanfc@gmail.com
} 


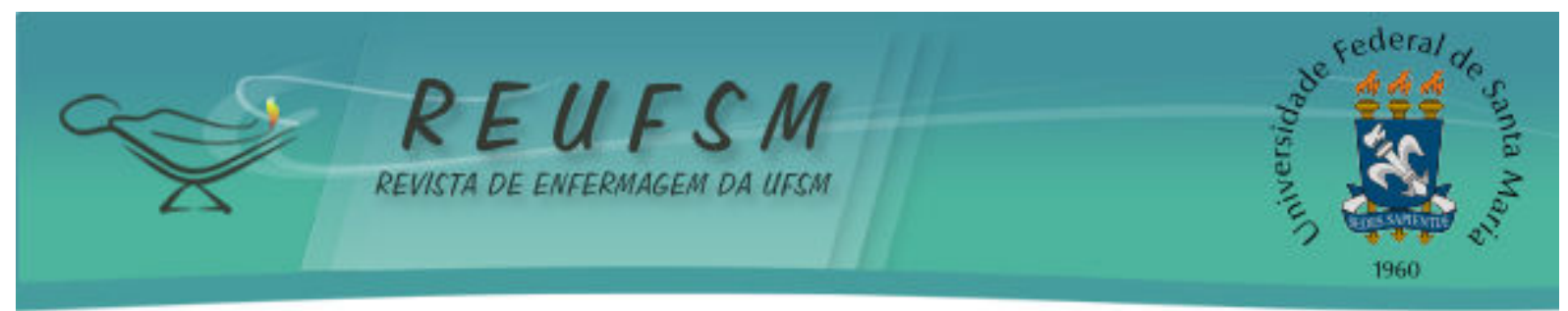

verified that female sexuality experience in the climacteric period has been influenced by cultural patterns established for female identity, which is related to the sexual satisfaction of the partner and the reproduction. Final considerations: it is necessary for nursing to develop educational activities in Health stimulating the discussion of sexuality, body, gender and violence, aiming to reflection of the male and female stereotypes.

Descriptors: Women's health; Climacteric; Sexuality; Gender identity.

RESUMEN: Objetivo: analizar la experiencia de mujeres en el climaterio con enfoque en la sexualidad. Método: estudio analítico-descriptivo y cualitativo, realizado con 16 mujeres de 35 a 65 años, usuarias de unidad básica de salud de la familia. La recogida de datos ocurrió en diciembre de 2010 mediante entrevista semiestructurada que fueron analizados según el análisis de contenido. El estudio cumplió con los requisitos para investigaciones con seres humanos, siendo aprobada por el CEP, CAAE $n^{\circ}$ 0484.0.133.00010. Resultados: la experiencia de la sexualidad en el climaterio posee influencia de los padrones culturalmente construidos alrededor de la identidad femenina, que relegan el papel de la mujer a la satisfacción del compañero y la reproducción. Consideraciones finales: se necesita que la enfermería desarrolle actividades de educación en salud que promuevan la discusión de temáticas como cuerpo, género y violencia, con el objetivo de fomentar la reflexión de los estereotipos de feminidad y masculinidad.

Descriptores: Salud de la mujer; Climatérico; Sexualidad; Identidad de género.

\section{INTRODUÇÃO}

O climatério consiste em uma fase do ciclo vital feminino, situado entre os 35 e os 65 anos de idade, marcado pela transição entre o período reprodutivo e o não reprodutivo. Estima-se que $32 \%$ das mulheres no Brasil estão nessa faixa etária. ${ }^{1}$

A atenção à mulher nesse período de sua vida está prevista nas diretrizes e objetivos da Política Nacional de Atenção Integral à Saúde da Mulher. Tal direcionamento, exige a inclusão, na agenda profissional, de atividades que contemplem a promoção da qualidade de vida desse grupo, ampliando o escopo do cuidado para além dos aspectos biológicos. ${ }^{1}$

Neste sentido, as demandas de cuidado à mulher no climatério tem solicitado uma abordagem profissional multidisciplinar, acentuando o compromisso e a importância da atuação dos enfermeiros. Sendo assim, destaca-se que as ações de cuidado devem ser pautadas na compreensão da influência do contexto social e cultural e da forma como a mulher vê o climatério e, acima de tudo, favorecendo a compreensão das mudanças que ocorrem, para que a mulher seja capaz de vivenciar essa fase livre de mitos e preconceitos. ${ }^{2}$

Diversas transformações fazem parte do climatério, tais como mudanças hormonais, estéticas, psicológicas e culturais, que podem resultar em significativo impacto para a sexualidade feminina.

A influência das modificações biológicas sobre a sexualidade no climatério tem sido alvo de diversos estudos. As consequências endócrinas da diminuição da secreção de esteroides ovarianos têm sido apontadas como causas para alterações físicas que, por sua vez, provocam desconforto e alteram a resposta sexual. ${ }^{3-4}$ No entanto, a sexualidade no climatério deve ser compreendida também a partir de fenômenos não lineares, considerando a importância da associação entre a vivência individual e a dinâmica da intimidade emocional e da satisfação no relacionamento. ${ }^{5}$

Dessa forma, observa-se que sexualidade não é sinônimo de sexo, pois não se resume apenas ao intercurso sexual. Sua manifestação ocorre de diversas formas através da interação entre pessoas, seja pelo contato físico, carícia, sensualidade, entre outras formas, que não apenas 0 ato sexual propriamente dito. Diferencia-se em diversos 


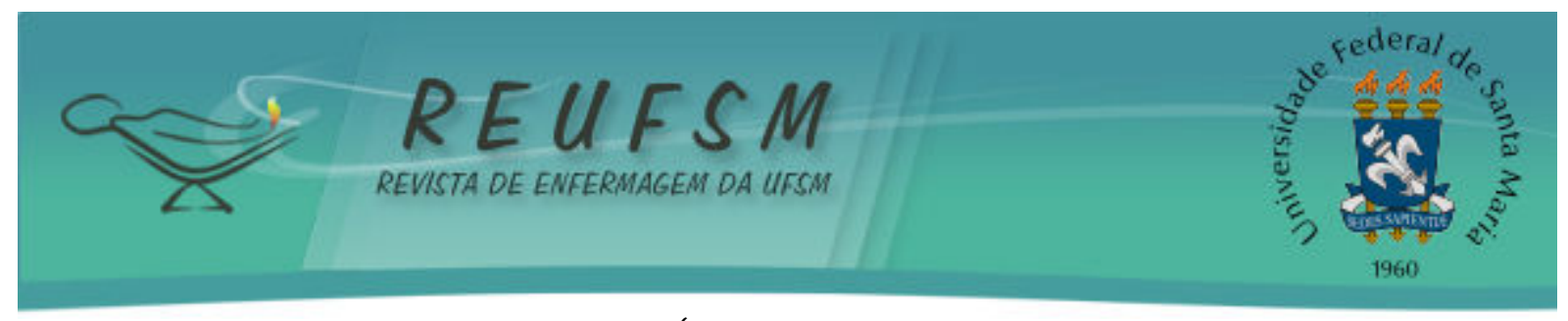

aspectos de acordo com cada cultura. ${ }^{6}$ Logo, a maneira como é vivenciada ou mesmo os valores atribuídos, dependerá da construção cultural de cada indivíduo.

A mulher, no período do climatério, observa modificações substanciais no tocante à sua sexualidade. Estas modificações são delimitadas e justificadas, pela mulher, como resultantes dessa fase do ciclo vital. ${ }^{7}$

Constituindo uma temática complexa, estudos que se apropriem do conhecimento empírico sobre o tema pode contribuir para a discussão e compreensão dos possíveis entraves na vivência da sexualidade feminina no climatério, corroborando para o desempenho das ações do cuidado em enfermagem mais próximos das necessidades das mulheres que vivenciam esse período.

Deste modo, este artigo objetivou analisar a vivência de mulheres no climatério com foco na sexualidade. Para o alcance deste objetivo foi utilizada a seguinte questão condutora: como a mulher vivencia sua sexualidade no climatério?

\section{MÉTODO}

Trata-se de um estudo analítico-descritivo, de natureza qualitativa, pois esse tipo de abordagem aplica-se ao estudo de relações, percepções e opiniões oriundas das interpretações que os sujeitos fazem sobre como vivem, sentem e pensam. ${ }^{8}$

A amostra constituiu-se por 16 mulheres, usuárias do Sistema Único de Saúde (SUS), na faixa etária compreendida entre 35 e 65 anos de idade. As usuárias foram convidadas a participar do estudo durante a visita ao serviço de saúde para o atendimento clínico de enfermagem ou médico. Destacamos que no serviço analisado, não há o desenvolvimento de atividades de saúde com foco nesse grupo, sendo que a atenção ocorre por meio apenas dos atendimentos clínicos relativos à prevenção do câncer de colo e detecção precoce do câncer de mama. A seleção das usuárias ocorreu de forma aleatória, porém estabeleceu-se como critério de inclusão: ser mulher e estar entre as idades do climatério; frequentar a Unidade Básica de Saúde da Família (UBSF) pesquisada e ter disponibilidade para participar da pesquisa. O cenário escolhido foi um bairro de periferia na Campina Grande/Paraíba, constituído por população de baixa renda, imerso em uma situação de marginalidade extrema e em um contexto de tráfico de drogas e de violência urbana.

Para composição do corpus de análise, foi utilizada a técnica da entrevista semiestruturada contendo questões que corresponderam ao objetivo do estudo. 0 instrumento continha dados de identificação e de questões que permitiram à mulher discorrer acerca da vivência da sexualidade climatério.

As entrevistas foram realizadas individualmente em ambiente reservado na própria unidade de saúde. As falas foram gravadas, não havendo limitação de tempo para as respostas, a fim de se tornar fiel a transcrição dos depoimentos. Considerando o anonimato, as mulheres foram identificadas pela letra $M$, seguida do número sequencial da entrevista.

A coleta do material empírico ocorreu no período de dezembro de 2010, após avaliação e aprovação da proposta pelo Comitê de Ética e Pesquisa, conforme CAAE $\mathrm{n}^{\circ}$ 0484.0.133.000-10, datado de 11 de novembro de 2010.

Considerando o que preconiza a Resolução $466 / 12^{9}$, que trata de pesquisa com seres humanos, as mulheres foram esclarecidas sobre o objetivo da pesquisa, bem como sobre a manutenção do sigilo, do anonimato e do direito de participar ou não da pesquisa. As participantes assinaram o termo de consentimento livre e esclarecido.

Para desenvolver o processo analítico, o material foi submetido à análise de conteúdo temática, visando descobrir o que está implícito em cada conteúdo manifesto verificando hipóteses e partindo do que está escrito, falado, figurativamente desenhado ou simbolicamente explicitado..$^{8-10}$ 


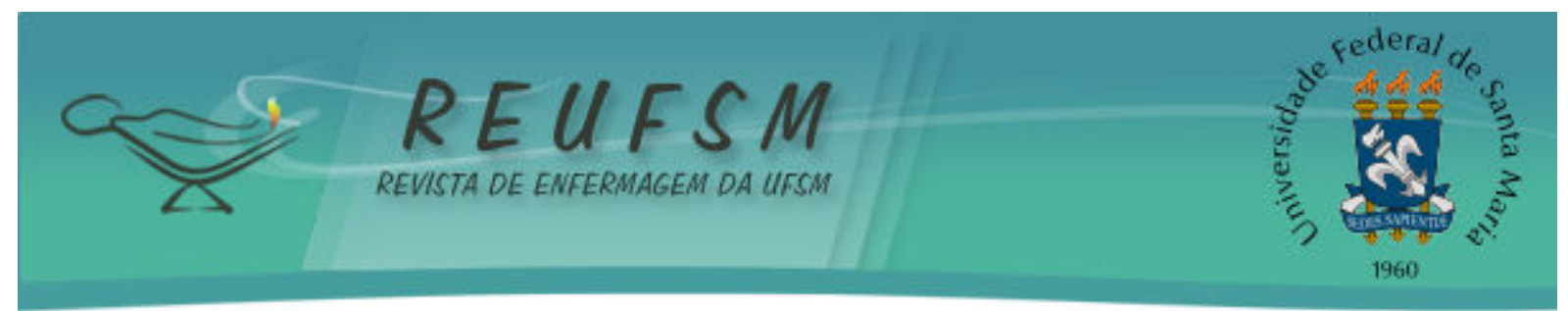

$\mathrm{Na}$ análise do material empírico foram extraídas as seguintes categorias: sexualidade e sexo; questões de gênero e a vivência da sexualidade; responsabilização pelas dificuldades na vivência da sexualidade. Os resultados e a discussão foram subsidiados por meio da literatura sobre a temática.

\section{RESULTADOS E DISCUSSÃO}

\section{Perfil das mulheres}

A faixa etária das entrevistadas variou entre 35 e 65 anos, predominando aquelas entre 40 a 49 anos de idade (56,2\%); quanto a raça/cor declarada, predominaram as pardas (44\%) e brancas (44\%); quanto ao grau de escolaridade, possuem o ensino fundamental incompleto $(62,5 \%)$, sendo que o maior nível de escolaridade foi o médio completo $(12,5 \%)$; a religião predominante foi a católica (75\%); a maioria desenvolve atividades não remuneradas $(62,5 \%)$, aquelas que recebem remuneração $(37,5 \%)$ referiram, na frequência de uma vez para cada, as atividades de comerciante, recepcionista, tesoureira, agricultora, auxiliar de serviços gerais e costureira; quanto ao estado civil declarado, predominaram as casadas $(37,5 \%)$ e separadas $(31,2 \%)$; a maior parte das mulheres tinham filhos $(87,5 \%)$, com maior percentual de três filhos ou mais $(68,8 \%)$.

A análise revelou que não há diferenças significativas nos relatos que indiquem um padrão de respostas distinto a partir do perfil da mulher. Esse dado indica que a vivência da sexualidade está imbricada por fatores que ultrapassam os aspectos geracionais e sociodemográficos, estando mais relacionados aos aspectos culturais.

\section{Sexualidade e sexo}

A maioria das entrevistadas $(56,2 \%)$ optou por não responder acerca da concepção sobre sexualidade, denunciando que este tema ainda é pouco discutido entre as mulheres, possivelmente, por se constituir em um tabu, sobretudo, pela estreita relação com sexo. ${ }^{11}$

Partindo da compreensão das dinâmicas de gênero e identidade social, o papel desempenhado pela mulher foi historicamente construído de forma assimétrica e em oposição ao papel masculino. A construção dicotômica dos papéis sexuais circunscreve a questão da sexualidade feminina ao âmbito privado. Portanto, essa discussão pode ser difícil para a maioria das mulheres, pois o modelo dominante, normativo, aceito socialmente, é o que corresponde ao sexo masculino, enquanto a feminina permanece velada em muitos contextos, reforçando crenças e padrões de comportamento entre elas. Nessa direção, o autoconhecimento se coloca como um desafio ainda, pois por fatores históricos e culturais, as mulheres são pouco instigadas às descobertas do corpo e, consequentemente, da sexualidade. ${ }^{12-14}$

Parte das entrevistadas relacionou a sexualidade ao ato sexual, enquanto as demais associaram a diversos sentimentos como amor e carinho.

Eu sei que sexualidade, assim, é esse lado, é sexo. (M15)

É a pessoa ter compreensão um com o outro, ter respeito, ter amor, amar o próximo que está ao seu lado, amar, ter carinho, ter compreensão. (M02)

De fato, a sexualidade envolve o ato sexual, mas também envolve a forma de sentir, considerando a subjetividade de cada ser sob diferentes perspectivas. ${ }^{2}$ Neste sentido, envolve 


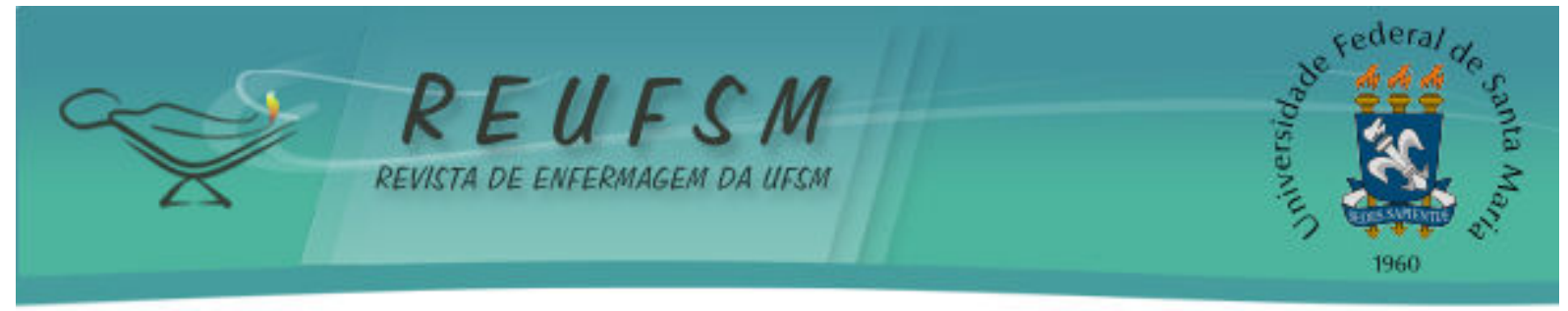

valores e práticas culturalmente legitimadas e, além da dimensão biológica, abrange à dimensão íntima e relacional que compõe a subjetividade das pessoas e suas relações. ${ }^{15}$

Sendo assim, a sexualidade é uma dimensão fundamental de todas as etapas da vida de mulheres e homens, presente desde o nascimento até a morte. Por essa razão, é necessário valorizar, promover e incentivar o autoconhecimento, que implica buscar conhecer a si mesma, seus valores, seu modo de ver e viver a sexualidade e a relação com o outro. ${ }^{12}$

\section{Questões de gênero e a vivência da sexualidade}

Quando incentivadas a revelar as motivações para a vivência da sexualidade de forma satisfatória, as entrevistadas apontaram o prazer e a necessidade de uma relação harmoniosa com seus companheiros.

Sentir amor e na hora sentir alguma coisa. (M16)

Precisa ter muito amor, né? Carinho, essas coisas, porque sem amor e sem carinho num relacionamento [pensativa]. (M13)

Sentimentos de confiança e relações afetuosas são fatores que tornam as mulheres mais felizes e dispostas a vivenciar a sexualidade satisfatoriamente.

Embora o questionamento inicial conduzisse a uma proposição positiva sobre a vivência da sexualidade, no decorrer das falas as mulheres revelavam a insatisfação com o relacionamento que mantinham.

O que me motiva a ter relação sexual [pensativa], eu acredito que é meu papel de mulher, a mulher ter o marido que sabe que é direito [...] antigamente, era tudo de bom [risos] agora quanto menos melhor. (M11)

Os relatos indicam os aspectos marcados pelas especificidades de gênero na sexualidade, pois a mulher constrói suas vivências a partir dos aspectos subjetivados culturalmente, em que o papel feminino tem sido restrito a satisfazer o companheiro e a reproduzir, reprimindo o seu desejo sexual.

Quando eu tinha [relações sexuais] era mais para agradar meu marido e ter filho. (M06)

Poucas mulheres referem o próprio desejo sexual como um fator biológico, estando frequentemente mais relacionado ao desejo de estar emocionalmente mais próxima do parceiro.

Praticar a sexualidade não é ter apenas uma vida sexual ativa, mas ter afeto por parte do parceiro, se sentir cuidada e protegida, incluindo o outro como um ser importante para a vida. Quando a relação não se traduz em afeto, ignora-se a realização pessoal. ${ }^{15}$

Todavia, as mulheres revelaram o desinteresse pela prática sexual e apresentaram como motivos as modificações no climatério (diminuição da libido).

Para mim tanto faz tanto fez, não sou muito chegada, a idade avançada, aí a gente perde o talento que temos, nova é uma coisa, quando vai ficando velha é outra. (M12) 


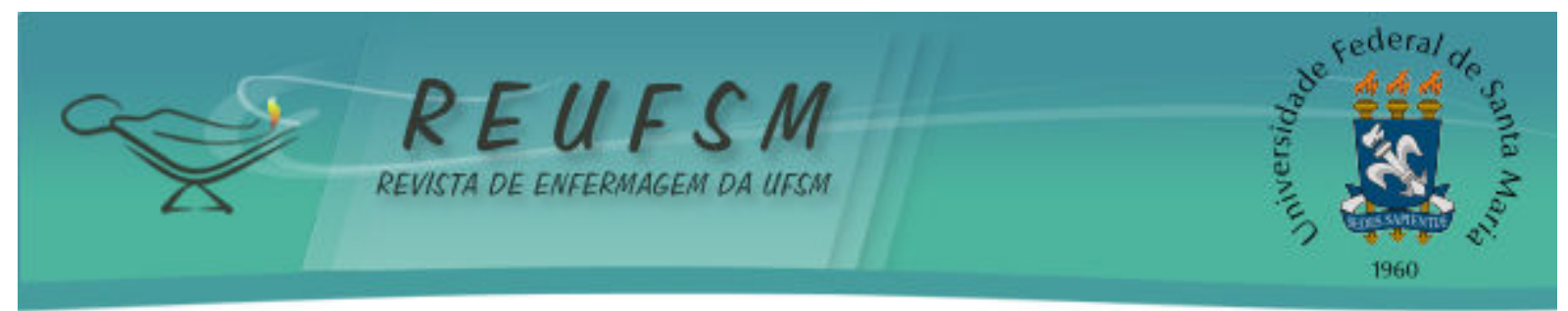

Para uma mulher saudável o climatério não é um fator isolado para diminuição do interesse por sexo e nem do seu potencial sexual. ${ }^{6} 0$ que altera, na verdade, é o tipo de resposta sexual, a qual se torna mais lenta e menos intensa em consequência da diminuição de estrogênio, não havendo relação com menor prazer e satisfação. Todavia, as modificações no climatério podem se constituir em um subterfúgio inconsciente para evitar relações sexuais que não oferecem satisfação.

0 desconhecimento e os tabus que delineiam a sexualidade durante o climatério acentuam as mudanças que acontecem no corpo e nas relações sexuais nesse período da vida, atribuindo, de forma equivocada, a diminuição do desejo à menopausa. A maior parte das barreiras não são propriamente sexuais, mas sim problemas e dificuldades que se refletem na vida sexual, como as normas e dinâmicas de gênero. A má qualidade de vida em geral é um dos fatores mais impeditivos do exercício pleno e da realização sexual, em qualquer fase da vida. ${ }^{11}$

\section{Responsabilização pelas dificuldades na vivência da sexualidade}

A vivência da sexualidade para algumas entrevistadas foi relatada como fonte de sofrimento sob diferentes aspectos.

As lágrimas desciam na hora. Eu fazia mais pra depois ele não dizer que eu tava atrás de outro homem, que não era. Porque ali eu não tava fazendo nada, porque eu nunca senti nada por ele mesmo. Só pela questão da convivência mesmo. Eu estou sendo sincera, está entendendo? Eu estou sendo sincera mesmo. Isso aí é toda a minha vida de 26 anos. (M16)

Percebe-se que as iniquidades de gênero e às representações de feminilidade e masculinidade interferem de forma decisiva na forma como as mulheres vivenciam sua sexualidade.

Ancorado na compreensão da construção social das diferenças de gênero, o conceito de feminilidade e masculinidade remete à dicotomia entre feminino e masculino, que baseado nas diferenças anatomofisiológicas legitima rótulos de comportamentos e criam modelos pretensamente naturalizados e opostos de ser mulher (inferior, frágil, passiva) e ser homem (superior, forte, ativo). Para a mulher o modelo de feminilidade, culturalmente construído, restringe a vivência da sexualidade à satisfação do parceiro em detrimento da compreensão do seu corpo como forma de obter amor, prazer e satisfação pessoal em qualquer fase da vida. ${ }^{2}$ Para o homem o modelo de masculinidade hegemônico direciona a vivência da sexualidade à potência, à resistência e à invulnerabilidade, o que conduz a uma prática restrita da sexualidade, tendo como marco da virilidade masculina o ato sexual. ${ }^{16}$

Observa-se que a mulher se responsabiliza pelo insucesso da relação.

Na hora da relação ele me procurava e eu não tinha mais vontade de fazer. (M02)

Por meio do discurso, é possível inferir que o processo de re/produção de sentidos faz parte de um trabalho social imbuído de ideologias, em que a língua naturaliza os sistemas de ideias socialmente construídos, em que a mulher, independente da posição que ocupa, é marcada por um coeficiente negativo, que afeta negativamente tudo que elas são e fazem. ${ }^{17}$ 


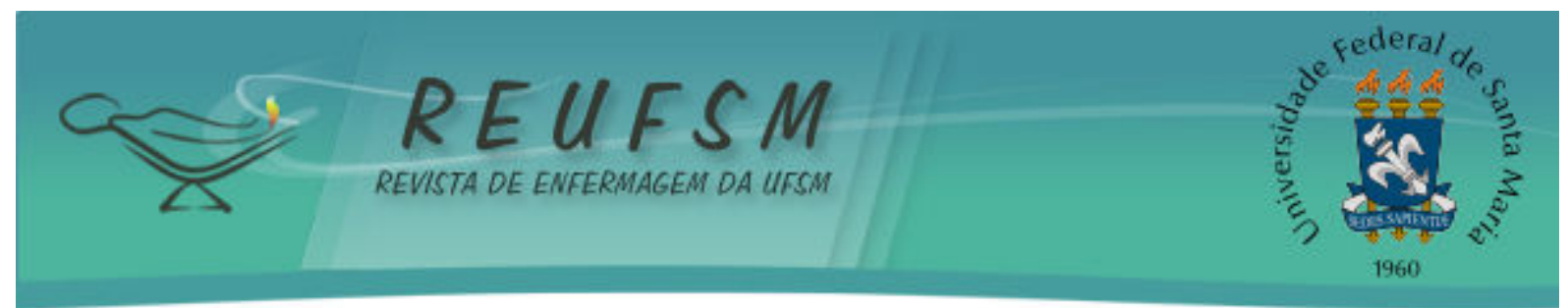

Entretanto, a partir da análise do contexto discursivo, o desinteresse sexual não tem como causa a redução do desejo, pois está relacionado a déficit de diálogo ${ }^{6}$ e por padrões modelados pelo androcentrismo, como atos violentos (físicos ou psicológicos) e o uso abusivo de bebidas alcoólicas. Reforça-se essa discussão adiante:

Por causa das cachaças que ele bebia, das coisas que ele fazia comigo e eu tomei nojo, assim ódio mesmo. (U16)

Ele tem 84 anos, me procura e eu não quero nem saber mais dessas coisas, ai ele diz que eu estou com outro. Eu não tenho vontade nem com ele, quanto mais com outro. (M02)

A responsabilização pelo pouco interesse por questões ligadas a sexualidade também foi relacionada ao processo de envelhecimento.

Mas também não sinto o mesmo na relação como antes sentia. Tudo parece mais difícil quando a gente começa a envelhecer. (M08)

Para mim tanto faz tanto fez, não sou muito chegada, a idade avançada, aí a gente perde o talento que temos. (M12)

Ele não é mais como antes, mas deve ser porque a gente já está ficando de idade. (M07)

Para as mulheres que compreendem a sexualidade de uma maneira mais ampla, na qual o amor, o carinho, os abraços, a cumplicidade são elementos centrais, o sexo representa um complemento. ${ }^{18}$ Portanto, somado às mudanças fisiológicas, vivências insatisfatórias no campo da sexualidade podem repercutir em desinteresse e desmotivação para prática sexual.

Embora as mulheres não referissem diretamente a responsabilidade do parceiro na redução do interesse nas relações sexuais, a diminuição da libido, por parte das mulheres, é uma mudança observada pelos companheiros, sendo aceita por aqueles que possuem informações sobre as alterações que ocorrem no período climatério.

Eu fiquei geladeira! Mas ele trabalha na área de saúde, ele me entende. (M11)

Entretanto, a compreensão compartilhada pelo parceiro não se refletiu em práticas e atitudes que promovessem estratégias de superação das dificuldades na esfera sexual. Observou-se que a conquista do prazer e da satisfação no campo da sexualidade é uma tarefa estranha aos companheiros.

Porque se ele fosse um homem que tivesse percebido alguma coisa em mim, eu não tinha me separado dele. (M16)

Aspectos subjetivos, tais como a receptividade feminina à estimulação sexual e a disponibilidade masculina em lidar com as alterações comuns no climatério, podem favorecer uma melhor vivência nessa fase. 


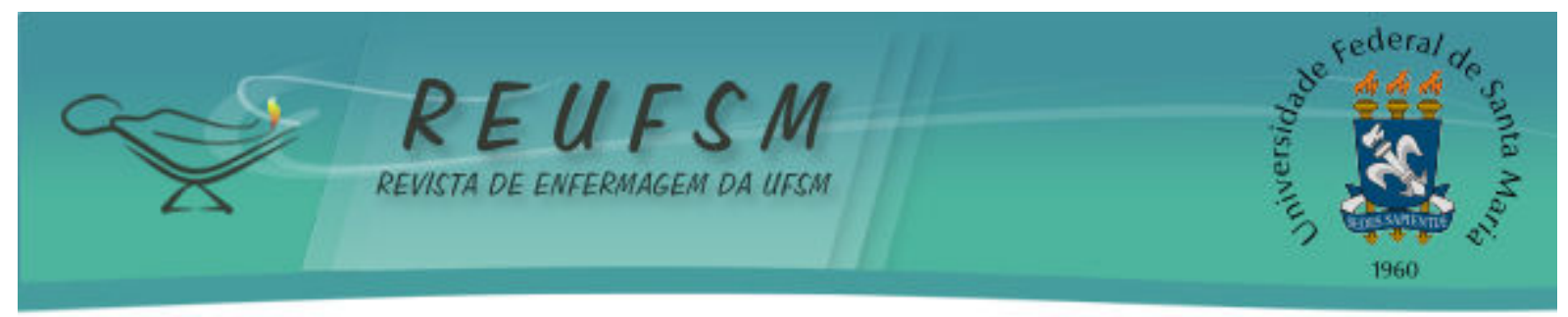

\section{CONSIDERAÇÕES FINAIS}

A sexualidade no climatério é permeada por diversas transformações, resultado da interação entre fatores biológicos, psicológicos e culturais. A dimensão destas transformações na esfera individual decorre do modo como cada sujeito vivencia sua sexualidade.

No contexto analisado, verifica-se que a vivência da sexualidade feminina no climatério possui influência dos padrões culturalmente construídos em torno da identidade feminina, que relegam o papel da mulher à satisfação do parceiro e à reprodução. Como reflexo disso, os discursos revelam o desencantamento com as questões relativas à sexualidade, sobretudo, com a atividade sexual. Apesar de sofrer com os desdobramentos da vivência da sexualidade de forma insatisfatória, as mulheres não identificam estratégias de superação dessas dificuldades.

Para a vivência plena da sexualidade aponta-se a relevância de uma abordagem positiva e respeitosa, possibilitando uma vivência prazerosa, livre de coerção e violência. Sendo assim, percebe-se a necessidade da ampliação na rede de saúde do acesso das mulheres a serviços que contemplem as questões que envolvem o climatério.

Assim, destaca-se que a equipe de saúde, sobretudo a enfermagem, tem papel fundamental na adoção de práticas que promovam uma melhor qualidade de vida durante e após o climatério. Acredita-se que o enfermeiro pode contribuir para desconstruir mitos e preconceitos que permeiam a sexualidade na esfera biológica e cultural. Para tanto, torna-se necessário o investimento em estratégias, como a educação em saúde, que promovam entre mulheres e homens a discussão de temas relativos à sexualidade, como corpo, gênero e violência, objetivando incentivar reflexões que desconstruam estereótipos arraigados de feminilidade e masculinidade e que limitam a vivência da sexualidade.

0 estudo traz como contribuição para a enfermagem a compreensão de que os entraves na vivência da sexualidade feminina no climatério necessitam de uma atenção voltada aos aspectos relacionais do cuidado, como as questões de gênero, e que transcendam os aspectos biológicos da assistência em saúde, favorecendo o cuidado em enfermagem mais próximo das necessidades das mulheres nessa fase.

Pelo fato do estudo ter sido desenvolvido apenas com mulheres, percebeu-se a necessidade do desenvolvimento de pesquisas que promovam a escuta masculina em torno das questões que envolvem a sexualidade em todas as fases da vida, sobretudo, no climatério.

\section{REFERÊNCIAS}

1. Brasil. Ministério da Saúde. Secretaria de Atenção à Saúde. Departamento de Ações Programáticas Estratégicas. Manual de atenção à mulher no climatério/menopausa. Brasília (DF): Ministério da Saúde; 2008. (Série A. Normas e Manuais Técnicos) (Série Direitos Sexuais e Direitos Reprodutivos; Caderno 9).

2. Valença CN, Nascimento Filho JM, Germano RM. Mulher no climatério: reflexões sobre desejo sexual, beleza e feminilidade. Saúde Soc [Internet]. 2010 jun [acesso em 2013 Abr 16];19(2):273-85.

Disponível

em:

http: / / www.scielo.br/scielo.php?script=sci_arttext\&pid=S0104-12902010000200005.

3. Nappi RE, Lachowsky M. Menopause and sexuality: prevalence of symptoms and impact on quality of life. Maturitas [Internet]. 2009Jun [cited $2013 \mathrm{Apr} 18] ; 63(2): 138-41$. Available from: http://www.sciencedirect.com/science/article/pii/S0378512209001108.

4. Lara LAS, Useche B, Silva JCR, Ferriani RA, Reis RM, Sá MFS, et al. Sexuality during the climacteric period. Maturitas [Internet]. 2009 Feb [cited 2013 Apr 18];62(2):127-33. Available from:http://www.sciencedirect.com/science/article/pii/S037851220800399X. 


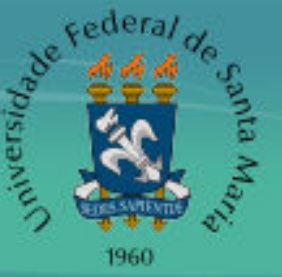

5. Pinto Neto AM, Valadares ALR, Costa-Paiva L. Climatério e sexualidade. Rev Bras Ginecol Obstet [Internet]. 2013 mar [acesso em 2013 abr 16];35(3):93-6. Disponível em: http://www.scielo.br/pdf/rbgo/v35n3/v35n3a01.pdf.

6. Costa GMC, Gualda DMR. Conhecimento e significado cultural da menopausa para um grupo de mulheres. Rev Esc Enferm USP [Internet]. 2008 mar [acesso em 2013 abr 18]; 42(1):81-9. Disponível em: http://www.scielo.br/pdf/reeusp/v42n1/11.pdf.

7. Oliveira DM, Jesus MCP, Merighi MAB. Climatério e sexualidade: a compreensão dessa interface por mulheres assistidas em grupo. Texto \& Contexto Enferm [Internet]. 2008 set [acesso em 2013 abr 17];17(3):519-26. Disponível em: http://www.scielo.br/pdf/tce/v17n3/a13v17n3.pdf.

8. Minayo MCS. O desafio do conhecimento: pesquisa qualitativa em saúde. $8^{a}$ ed. São Paulo: Hucitec; 2004.

9. Brasil. Ministério da Saúde. Conselho Nacional de Saúde. Resolução $n^{\circ}$ 466, de 12 de dezembro de 2012. Aprova diretrizes e normas regulamentadoras de pesquisas envolvendo

seres humanos e revoga as resoluções CNS $n^{\circ}$ os 196/96, 303/2000 e 404/2008. Brasília (DF): Conselho Nacional de Saúde; 2012 [acesso em 2013 dez 11]. Disponível em: http://conselho.saude.gov.br/resolucoes/2012/Reso466.pdf.

10. Minayo MCS. Pesquisa social: teoria, método e criatividade. Rio de Janeiro: Vozes; 2003. $108 \mathrm{p}$.

11. Gonçalves RL, Bezerra JMD, Costa GMC, Celino SDM, Santos SMP, Azevedo EB. The experience of sexuality through the view of women during pregnancy. J Nurs UFPE on line [Internet]. 2013 jan [acesso em 2013 abr 17];7(1):196-204. Disponível em: http://www.revista.ufpe.br/revistaenfermagem/index.php/revista/article/viewArticle/33 36.

12. Ministério da Saúde (BR). Secretaria de Atenção à Saúde. Departamento de Atenção Básica. Saúde sexual e saúde reprodutiva. Brasília (DF): Ministério da Saúde; 2010. (Série A. Normas e Manuais Técnicos)(Cadernos de Atenção Básica; 26).

13. Cruz VD, Fernandes GFM, Gomes VLO, Fonseca AD, Bordignon SS, Tomaschewski-Barlem JG. Sexuality female: perception of users at a basic family health unit. J Nurs UFPE on line [Internet]. 2012 ago [acesso em 2013 abr 17];6(8):1893-900. Disponível em: http://www.revista.ufpe.br/revistaenfermagem/index.php/revista/article/viewArticle/28 82.

14. Wünsch S, Oliveira SG, Garcia RP, Domingues IB. Coleta de citopatológico de colo uterino: saberes e percepções de mulheres que realizam o exame. Rev Enferm UFSM [Internet]. 2011 set/dez [acesso em 2013 abr 16];1(3):360-8. Disponível em: http://cascavel.ufsm.br/revistas/ojs-2.2.2/index.php/reufsm/article/view/2543/2385.

15. Gonçalves R, Merighi MAB. Reflections on sexuality during the climacteric. Rev Latinoam Enferm [Internet]. 2009 abr [acesso em 2013 abr 18];17(2):160-6. Disponível em: http://www.scielo.br/pdf/rlae/v17n2/pt_04.pdf.

16. Marques Junior JS, Gomes R, Nascimento EF. Masculinidade hegemônica, vulnerabilidade e prevenção ao HIV/AIDS. Ciênc Saúde Coletiva [Internet]. $2012 \mathrm{fev}$ [acesso em 2013 maio 30]; 17(2):511-20. Disponível em: http://www.scielosp.org/pdf/csc/v17n2/a24v17n2.pdf.

17. Bourdieu P. A dominação masculina. 4ạ ed. Rio de Janeiro: Bertrand Brasil; 2005. 


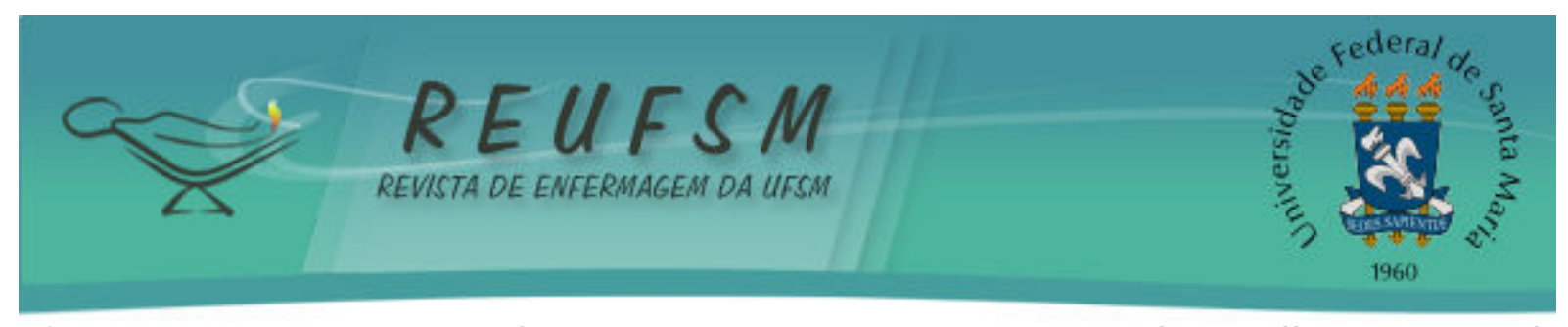

18. Biasus F, Demantova A, Camargo BV. Representações sociais do envelhecimento e da sexualidade para pessoas com mais de 50 anos. Temas Psicol [Internet]. 2011 jun [acesso

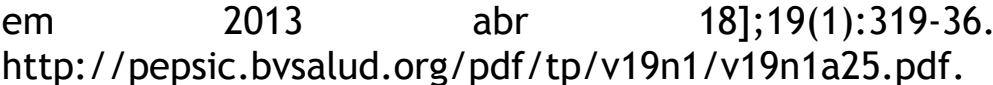

Data de recebimento: 28/04/2013

Data de aceite: $23 / 12 / 2013$

Contato com autor responsável: Sheila Milena Pessoa dos Santos

Endereço postal: Universidade Federal de Campina Grande, Centro de Ciências Biológicas e da Saúde, Curso de Enfermagem, Av. Juvêncio Arruda, 795, Bairro Bodocongó, CEP: 58109790 - Campina Grande (PB), Brasil

E-mail: sheila.milena@gmail.com 